\title{
Damage Tolerance of Alloy 718 Turbine Disc Material
}

\author{
M. Chang*, P. Au**, T. Terada ${ }^{* *}$, and A.K. Koul ${ }^{* *}$ \\ * Dept of Mechanical and Aerospace Engineering, \\ Carleton University, Ottawa, Canada \\ ** Structures and Materials Laboratory, \\ Institute for Acrospace Research, \\ National Research Council of Canada, Ottawa, Canada
}

\begin{abstract}
The influence of a modified heat treatment (MHT) and the standard heat treatment (SIIT) on the microstructure and mechanical properties of Alloy 718 turbine disc material has been studied over a range of temperatures varying between room temperature and $650^{\circ} \mathrm{C}$. The influence of these heat treatments has been studied on creep, low cycle fatigue (LCF), and fatigue crack growth rate (FCGR) properties. Test results have shown that the MHT improves the creep rupture life at $650^{\circ} \mathrm{C}$ but results in a loss of LCF crack initiation life at room temperature and $525^{\circ} \mathrm{C}$. The FCGRs of MHT and SHT materials are very similar at room temperature but the MHT improves the FCGR's of Alloy 718 at $525^{\circ} \mathrm{C}$ and $650^{\circ} \mathrm{C}$ over a wide range of $\Delta K$ values. The MHT material is cyclically more stable than the SHT material at all test temperatures. The notch sensitivity of Alloy 718 is also discussed.
\end{abstract}

Superalloys 1992

Edited by S.D. Antolovich, R.W. Stusrud, R.A. MacKay,

D.L. Anton, T. Khan, R.D. Kissinger, D.L. Klarstrom

The Minerals, Metals \& Materials Society, 1992 


\section{Introduction}

A damage tolerant microstructural design philosophy for turbine disc materials has been developed by Koul et al [1] where microstructures are designed to reduce elevated temperature creep and fatigue crack growth rates (CCGRs and FCGRs) with minimal loss in low cycle fatigue (LCF) crack initiation life. As a test case, a modified heat treatment (MHT) was developed for Alloy 718 turbine disc material to demonstrate the viability of these microstructural design concepts. The MHT produces a coarser grain size relative to the standard heat treatment (SHT) and it also produces a serrated grain boundary structure in Alloy 718 through controlled precipitation of needle like $\delta$ phase at the grain boundaries. A coarse grain size and the presence of serrations are expected to suppress grain boundary sliding and the serrations are also expected to make the crack path more tortuous. Previous test results at $650^{\circ} \mathrm{C}$ showed that, compared to the SHT, the MHT substantially decreased the FCGRs and CCGRs of Alloy 718. However, this benefit was also accompanied by a small reduction in LCF crack initiation life. It has been suggested that the loss in LCF life in Alloy 718 subjected to MHT occurs due to its lower yield strength and the presence of a larger grain size [1-3].

A turbine disc is always subjected to radial temperature variation where the bore regions may be exposed to temperatures as low as $150^{\circ} \mathrm{C}$, the bolt hole regions may be exposed to intermediate temperatures of the order of $500-550^{\circ} \mathrm{C}$, and the rim may be subjected to temperatures as high as $600-760^{\circ} \mathrm{C}$. In this work, the LCF and FCGR results of the SHT and MHT materials are compared at room temperature (RT) and $525^{\circ} \mathrm{C}$. Creep properties of the two materials are also compared at $650^{\circ} \mathrm{C}$.

\section{Experimental Materials}

\section{Experimental Materials and Test Methods}

The commercially available hot rolled Alloy 718 was produced in the form of $22 \mathrm{~mm}$ diameter bars and $12.7 \mathrm{~mm}$ thick $\times 50.8 \mathrm{~mm}$ wide plates. The bar and the plate materials were from two different heats and their chemical compositions are given in Table 1. The bar was used for machining LCF specimens whereas the plate was used for machining FCGR and creep specimens.

Table 1. Composition of Experimental Alloy 718 Materials in wt.\%

\begin{tabular}{lccccccccc}
\hline Stock Type & $\mathrm{Ni}$ & $\mathrm{Cr}$ & $\mathrm{Nb}+\mathrm{Ta}$ & $\mathrm{Mo}$ & $\mathrm{Ti}$ & $\mathrm{Al}$ & $\mathrm{Si}$ & $\mathrm{C}$ & $\mathrm{Fe}$ \\
\cline { 1 - 8 } Bar & 53.2 & 18.3 & 5.17 & 3.0 & 1.0 & 0.42 & 0.12 & 0.03 & Bal. \\
Plate & 53.1 & 17.9 & 5.11 & 3.06 & 0.96 & 0.47 & 0.21 & 0.05 & Bal. \\
\hline
\end{tabular}

Each material was examined in the SHT and MHT conditions. The two heat treatment schedules are presented in Table 2. The average grain sizes of the bar and the plate materials after SHT and MHT are also presented in Table 2.

\section{Mechanical Testing}

Round creep specimens, conforming to ASTM E-8 specifications, were machined from the heat treated plate material with specimen axis perpendicular to the plate rolling direction. Constant load creep-rupture tests on SHT and MHT materials were conducted at $650^{\circ} \mathrm{C}$ in laboratory air at an initial stress of $593 \mathrm{MPa}$. Creep extension was monitored with an LVDT connected to an extensometer attached to the specimen shoulders.

Axial LCF specimens, conforming to ASTM E606 specifications, were machined from the heat treated bars and the test section of each specimen was polished manually. Strain 
controlled LCF tests were conducted on both SHT and MHT materials at RT and $525^{\circ} \mathrm{C}$, using a triangular waveform and a constant strain rate of $0.002 / \mathrm{sec}$ at $0.1 \mathrm{~Hz}$ and an $\mathrm{R}$ value of -1 .

Statistically significant FCGR data bases were generated on standard $50.8 \mathrm{~mm}$ wide and $12.7 \mathrm{~mm}$ thick compact tension (CT) specimens, conforming to ASTM E647 specifications, at RT and $525^{\circ} \mathrm{C}$ in laboratory air. Five CT specimens per material condition were tested at a given temperature. All CT specimens were precracked at RT and FCGR tests were conducted at an $R$ value of 0.1 and a frequency of $1 \mathrm{~Hz}$. The specimen notch was oriented parallel to the rolling direction. A direct current potential drop (DC-PD) technique was used to monitor the crack lengths during FCGR testing [4]. The yield strength, modulus of elasticity, and hardness of the materials were also measured.

Table 2. Heat Treatment Schedules Used on Experimental Alloy 718 Materials

\begin{tabular}{|c|c|c|c|}
\hline $\begin{array}{l}\text { Heat } \\
\text { Treatment }\end{array}$ & Heat Treatment Schedule & $\begin{array}{l}\text { Average } \\
\text { Grain Size } \\
\text { ASTM \# }\end{array}$ & $\begin{array}{l}\text { Grain Boundary } \\
\text { Morphology }\end{array}$ \\
\hline SHT & $\begin{array}{l}955^{\circ} \mathrm{C} / 1 \mathrm{hr} / \mathrm{AC}+ \\
718^{\circ} \mathrm{C} / 8 \mathrm{hr} / \mathrm{FC} \rightarrow 1^{\circ} \mathrm{C} / \mathrm{min} \rightarrow 621^{\circ} \mathrm{C} / 8 \mathrm{hr} / \mathrm{AC}\end{array}$ & $\begin{array}{l}8 \text { (plate) } \\
10 \text { ( bar ) }\end{array}$ & Planar \\
\hline MHT & $\begin{array}{l}1032^{\circ} \mathrm{C} / 1 \mathrm{hr} / \mathrm{FC} \rightarrow 3^{\circ} \mathrm{C} / \mathrm{min} \rightarrow 843^{\circ} \mathrm{C} / 4 \mathrm{hr} / \mathrm{AC}+ \\
926^{\circ} \mathrm{C} / 1 \mathrm{hr} / \mathrm{FC} \rightarrow 3^{\circ} \mathrm{C} / \mathrm{min} \rightarrow 718^{\circ} \mathrm{C} / 8 \mathrm{hr} / \mathrm{FC} \rightarrow \\
1.6^{\circ} \mathrm{C} / \mathrm{min} \rightarrow 621^{\circ} \mathrm{C} / 8 \mathrm{hr} / \mathrm{AC}\end{array}$ & $\begin{array}{l}4 \text { (plate) } \\
3 \text { ( bar) }\end{array}$ & Serrated \\
\hline
\end{tabular}

\section{Tensile Properties}

\section{Results and Discussion}

The $0.2 \%$ offset yield strength and the modulus of elasticity of the SHT and MHT materials are compared in Table 3. These measurements were taken from the first stress-strain cycle during the LCF tests. Relative to the SHT material, the yield strength of the MHT material is lower at all test temperatures, confirming the suggestion made by Antolovich [2] that the precipitation of grain boundary $\delta$ (orthorhombic $\mathrm{Ni}_{3} \mathrm{Nb}$ ) phase in the MHT material reduces the amount of matrix $\mathrm{Nb}$ content available for $\gamma^{\prime \prime}\left(\mathrm{BCT} \mathrm{Ni}_{3} \mathrm{Nb}\right)$ precipitation. The difference in the RT hardness values between the two materials is consistent with the yield strength results. The modulus of elasticity of the two materials are comparable at all test temperatures.

Table 3. Mechanical properties of Alloy 718

\begin{tabular}{lllll}
\hline \hline Temp. & & Hardness $(\mathrm{Rc})$ & $\sigma_{\mathrm{ys}}(\mathrm{MPa})$ & $E(\mathrm{MPa})$ \\
\hline \multirow{2}{*}{$\mathrm{RT}$} & SHT & 46.5 & 1204 & $198 \times 10^{3}$ \\
& MHT & 44.5 & 1036 & $199 \times 10^{3}$ \\
$525^{\circ} \mathrm{C}$ & SHT & & 1066 & $173 \times 10^{3}$ \\
& MHT & & 876 & $172 \times 10^{3}$ \\
$650^{\circ} \mathrm{C}[3]$ & SHT & & 970 & $168 \times 10^{3}$ \\
& MHT & & 827 & $168 \times 10^{3}$ \\
\hline
\end{tabular}

Optical micrographs showing the microstructures of the longitudinal sections of the bar and the plate materials subjected to the SHT and MHT arc presented in Fig.1. The average grain sizes for both materials are compared in Table 2 . It is clear that the MHT produces 
serrated grain boundaries in Alloy 718 and leads to an increase in grain size. The plate material, however, revealed the presence of a heavily banded grain structure and these bands were retained even after the higher solution treatment temperature used in the MHT, Fig.1(d). Alloy 718 is particularly prone to banded grain structure formation due to inhomogeneous distribution of MC carbides and the MC clusters help form fine grained bands in the wrought products. The MHT partially modifies these banded regions by solutioning some $\mathrm{NbC}$ carbides because of a higher solution treatment temperature than SHT $\left(1032 \mathrm{v} / \mathrm{s} 955^{\circ} \mathrm{C}\right)$ but a duplex grain size distribution is still retained. In finished forged or rolled products, complete elimination of carbide segregation and duplex grain size formation is only possible if the solution treatment temperature exceeds $1200^{\circ} \mathrm{C}$ but such a treatment would obviously lead to excessive grain growth. Recent investigation by Poole, Stultz and Manning [5] have clearly shown that banded region formation in Alloy 718 can be eliminated through proper ingot homogenization practice.

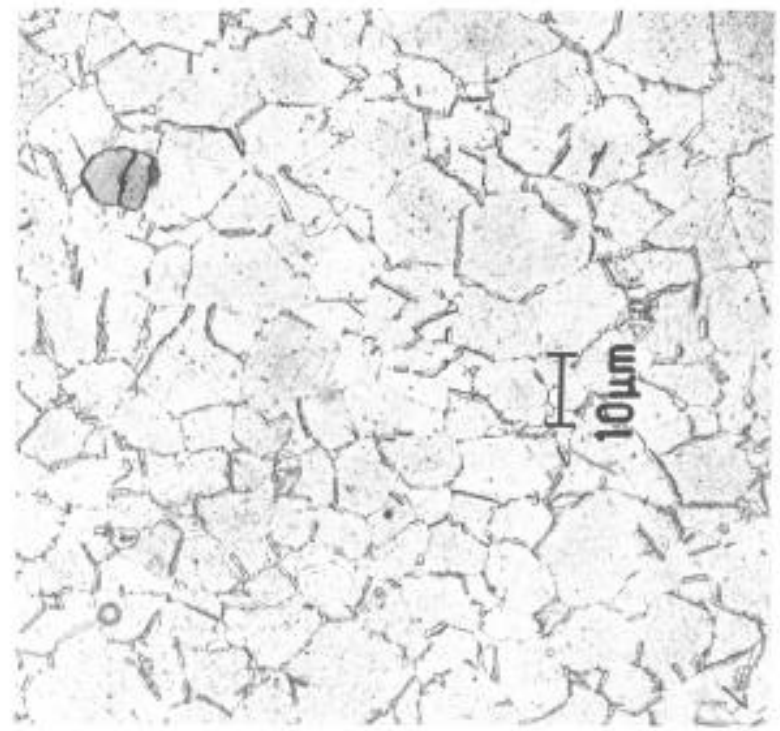

(a) Bar, SHT

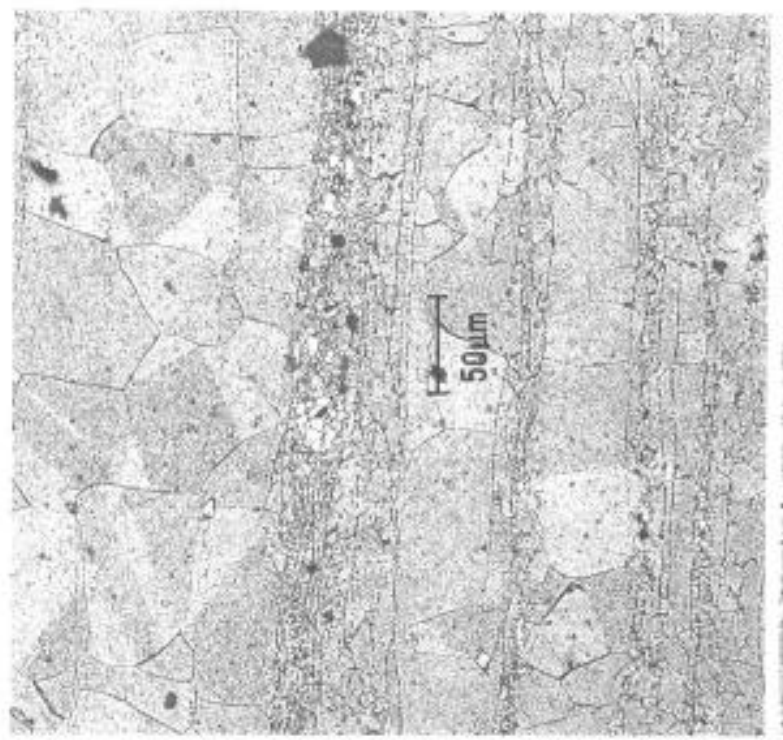

(c) Plate, SHT

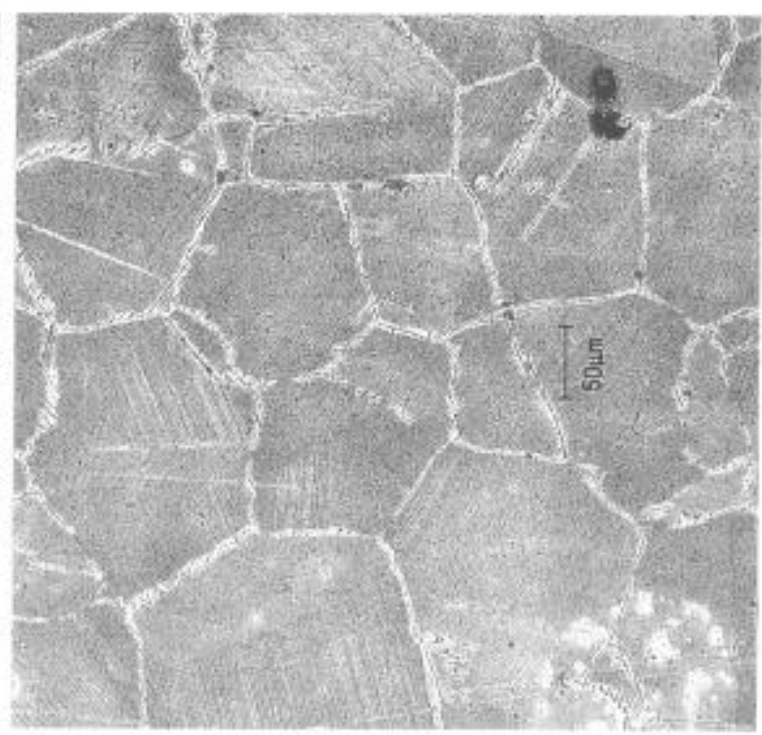

(b) Bar, MHT

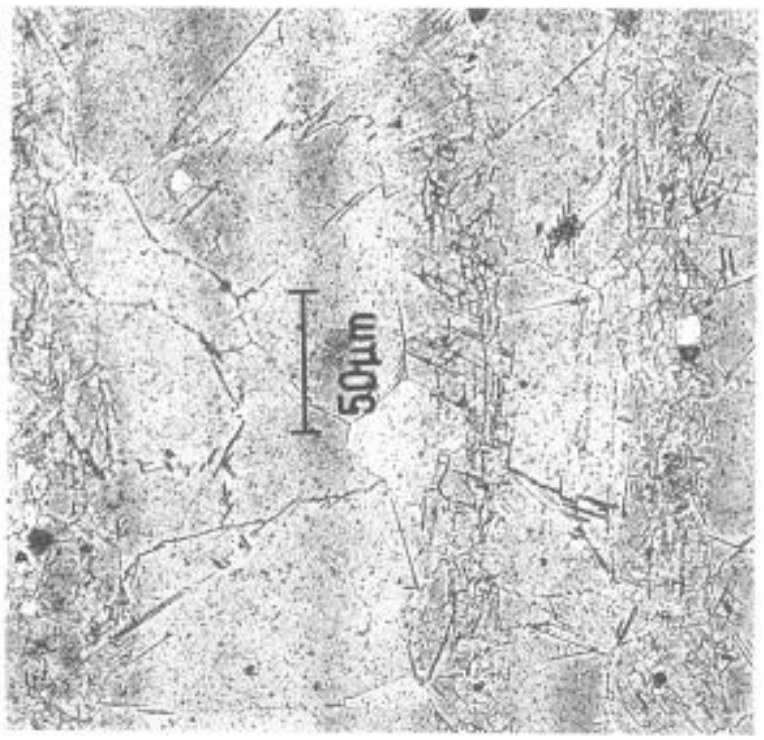

(d) Plate, MHT

Fig. 1 Microstructure of Alloy 718 bar and plate materials after SHT and MHT. 


\section{Creep Properties}

The creep curves for the two materials at $650^{\circ} \mathrm{C}$ are compared in Fig.2. It is evident that the minimum creep rates in both materials are very similar but the MHT improves rupture life by a factor of $\sim 1.5$ to 2 . The life improvement occurs as a result of extended tertiary creep in the MHT material. The creep fracture in the MHT material was predominantly transgranular whereas the SHT material primarily fractured intergranularly, Fig.3. These observations indicate that the presence of serrated grain boundaries and a relatively larger grain size suppress grain boundary sliding in the MHT material and promote transgranular deformation which leads to an increase in creep life. In Fig 3(c), it is interesting to note that creep cracks propagate preferentially along the fine grained regions of the banded structure in the SHT material. This behaviour may also have contributed to the short creep life of the SHT material.

The creep fracture strain of the MHT material (5-6\%) is marginally lower than the creep fracture strain observed in the SHT material (5-8\%). It is however difficult to judge the significance of these minor differences because of the limited number of tests $(3$ specimens per material condition) conducted during this investigation. These results are somewhat different from those reported for other Ni-base superalloys with rounded serrations where grain boundary serrations have been noted to improve creep ductility in short term creep tests [6].

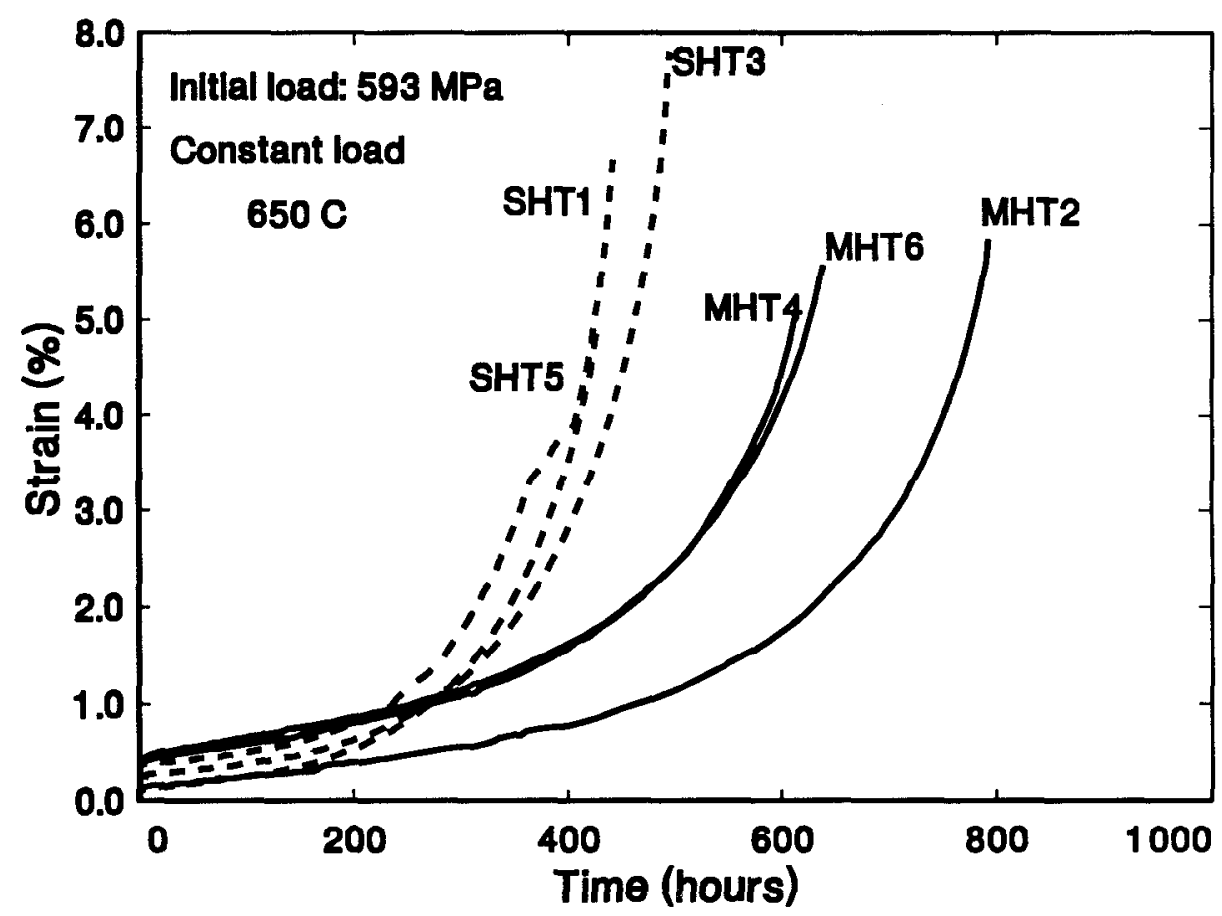

Fig. 2 Creep curves for SHT and MHT Alloy 718 generated at $650^{\circ} \mathrm{C}$ and $593 \mathrm{MPa}$.

\section{Fatigue Crack Growth Rate Behaviour}

At RT, the FCGRs of both MHT and SHT materials are similar, Fig.4(a), whereas at $525^{\circ} \mathrm{C}$, the FCGRs of the MHT material are lowered by a factor of $\sim 2$ over the entire Paris regime, Fig.4(b). A similar trend to that observed at $525^{\circ} \mathrm{C}$ has previously been reported for the MHT material at a test temperature of $650^{\circ} \mathrm{C} \mathrm{[1].} \mathrm{To} \mathrm{determine} \mathrm{the} \mathrm{statistical} \mathrm{significance}$ of these results, the upper bound lines (dashed and solid lines for SHT and MHT materials respectively in Fig.4), representing 3 conditional standard deviations from the mean lines, are superimposed for comparison. These results further confirm that the MHT is beneficial to Alloy 718 FCGRs at elevated temperatures [1]. In addition, it is significant that the MHT does not deleteriously influence the FCGRs of the Alloy 718 at room temperature. 


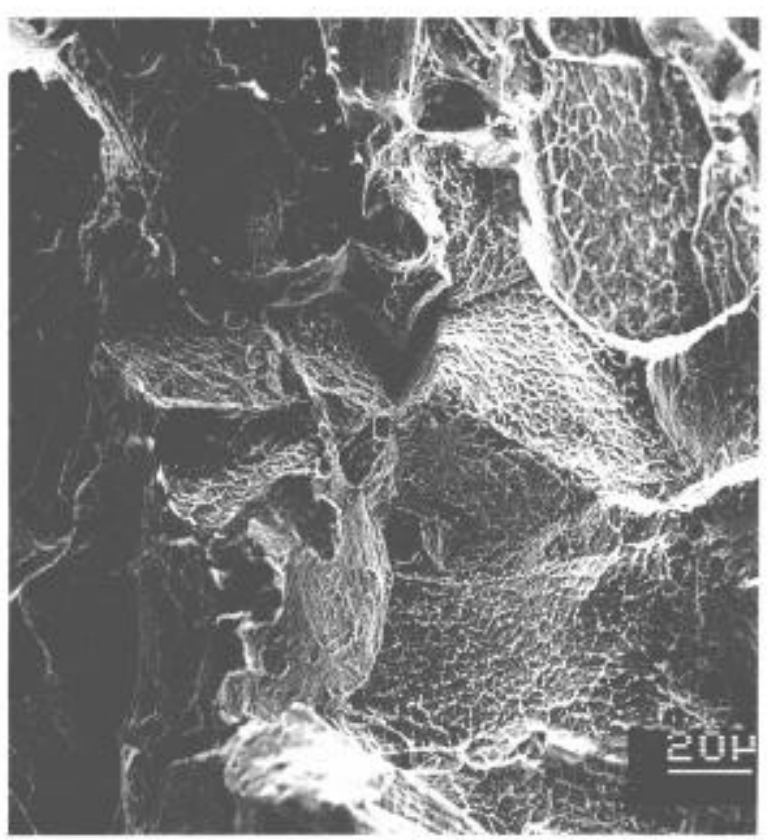

(a) SHT

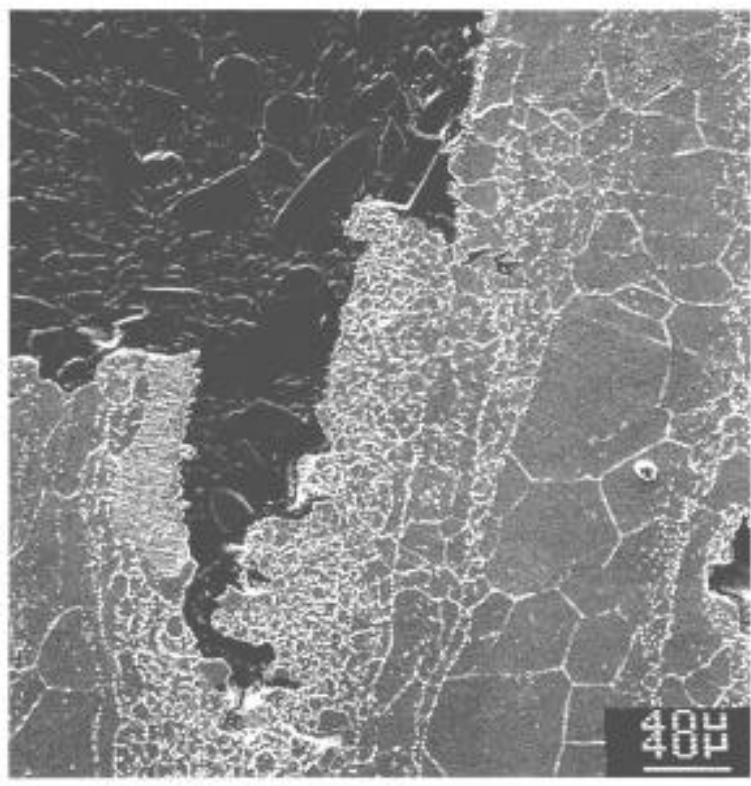

(c) SHT

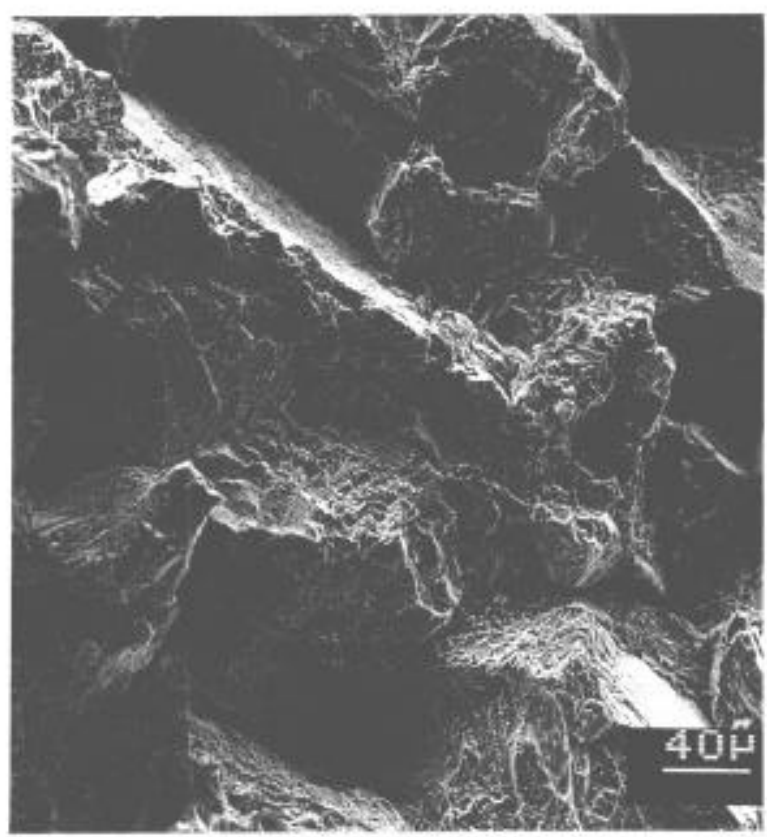

(b) MHT

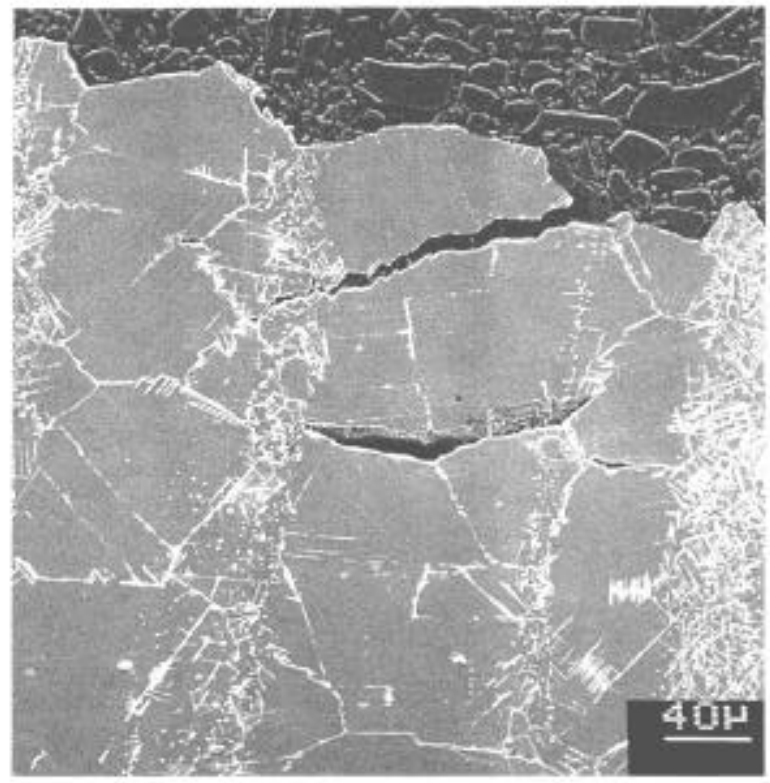

(d) MHT

Fig. 3 SEM micrographs showing the fracture surface morphology and creep crack paths in Alloy 718 creep specimens tested at $650^{\circ} \mathrm{C}$. (a) fracture SHT material, (b) fracture MHT material, (c) crack paths in SHT material, and (d) crack paths in MHT material.

The slope $(n)$ values for Paris regime, where FCGR behaviour is represented by $d a / d N$ $=C \Delta K^{n}$, are compared for the SHT and MHT materials at RT, $525^{\circ} \mathrm{C}$ and $650^{\circ} \mathrm{C}$ in Table 4 . The $n$ values decrease with increasing temperature for both materials but, at a given test temperature, the $n$ values for both SHT and MHT materials are comparable. The observed decrease in $n$ values with increasing temperature is consistent with the results obtained by James and Mills [7] where $n$ values were observed to decrease from 5.2 at $24^{\circ} \mathrm{C}$ to 1.9 at $650^{\circ} \mathrm{C}$. The temperature dependence of $n$ values is perhaps related to the change in the contribution of different deformation mechanisms within the plastic zone toward crack 
extension and the varying influence of environmental contribution towards crack growth with increasing temperature.

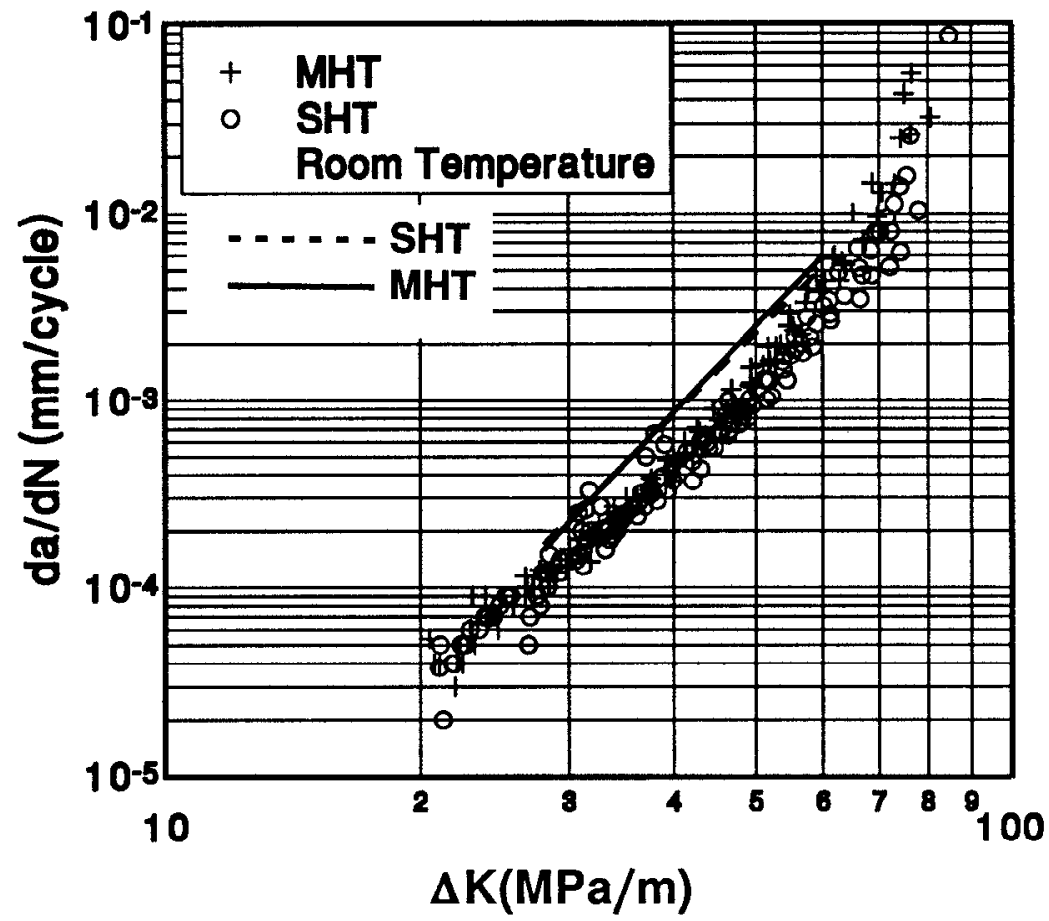

( a )

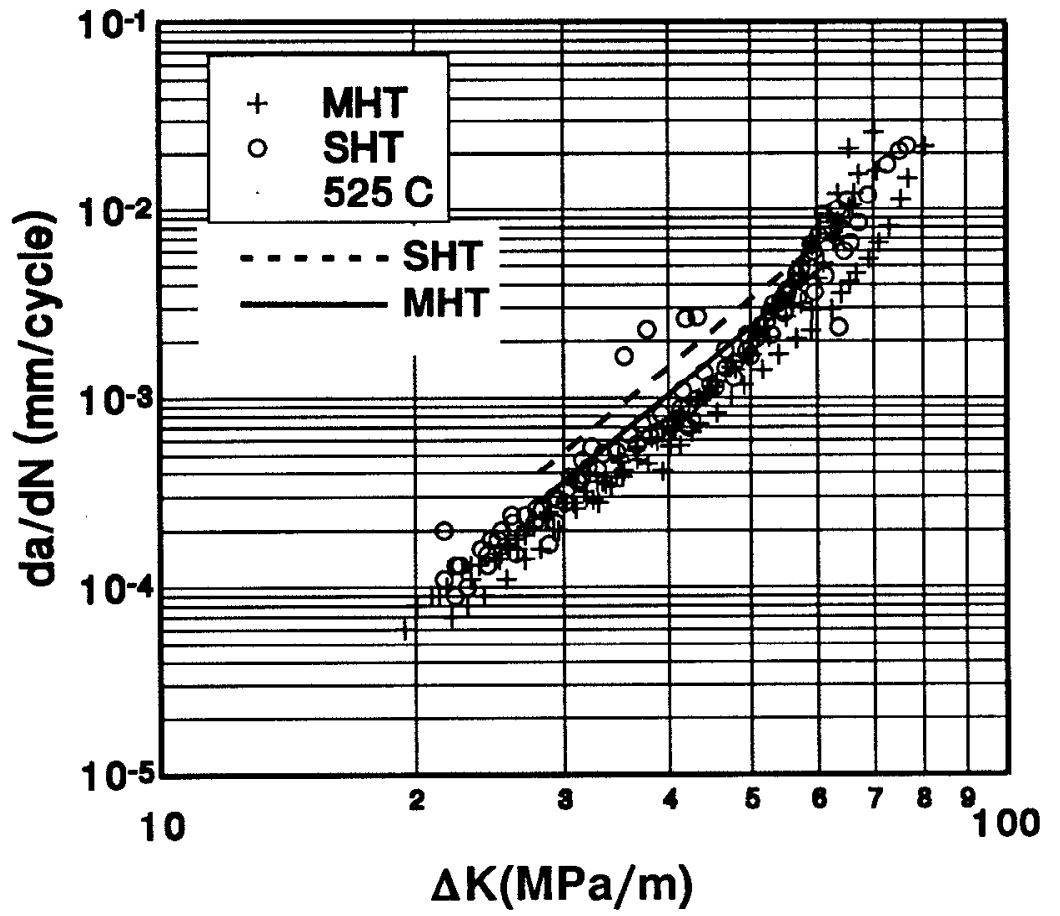

(b)

Fig. 4 Fatigue crack growth rate versus stress intensity range $(\Delta K)$ in MHT and SHT Alloy 718 materials at (a) RT and (b) $525^{\circ} \mathrm{C}$. 
Table 4. Comparison of Slopes for Paris Regime in SHT and MHT Materials

\begin{tabular}{lllllll}
\hline \hline & \multicolumn{2}{c}{ RT } & \multicolumn{2}{c}{$525^{\circ} \mathrm{C}$} & \multicolumn{2}{c}{$650^{\circ} \mathrm{C}[1]$} \\
& MHT & SHT & MHT & SHT & MHT & SHT \\
\hline$n$ & 3.99 & 3.62 & 3.37 & 3.18 & 2.45 & 2.53 \\
\hline
\end{tabular}

\section{Fatigue Crack Initiation Life}

The LCF crack initiation life data, as a function of total strain range, for the MHT and SHT materials are presented in Fig.5. Previous data, generated at $650^{\circ} \mathrm{C}$ [1], are also superimposed on Fig.5 for comparison. The LCF life of the MHT material is generally lower than the SHT material at all test temperatures but the differences are marked at RT. Relative to the SHT material, the LCF lives of the MHT material are lowered by almost factors of 3 , 2 and 1.5 at RT, $525^{\circ} \mathrm{C}$ and $650^{\circ} \mathrm{C}$ respectively. The lower LCF life of the MHT material is most likely related to its lower yield strength because damage accumulation is greater on a per cycle basis.

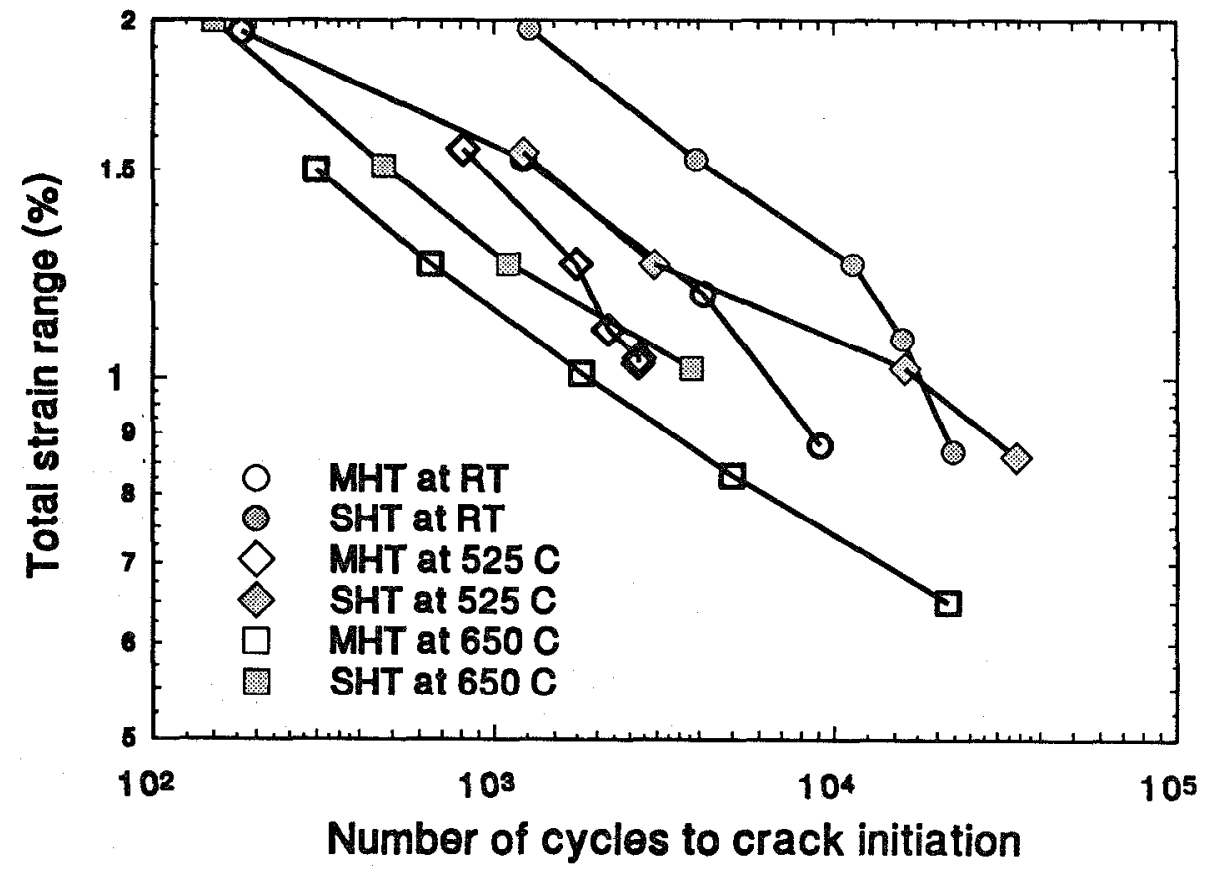

Fig. 5 Number of cycles to crack initiation $N$ versus total strain range $\Delta \varepsilon_{\mathrm{T}}$. Data for SHT and MHT Alloy 718 materials at RT, $525^{\circ} \mathrm{C}$ and $650^{\circ} \mathrm{C}$.

The monotonic and cyclic stress-strain curves for the two materials are compared in Fig.6. The MHT material is cyclically more stable than the SHT material at all test temperatures because it initially hardens and then softens marginally whereas the SHT material softens considerably before stabilizing at a steady state stress value. The cyclic softening of the SHT material is most likely related to the presence of fine $\gamma$ " discs which can lose coherency through interaction with dislocations or be sheared by dislocations during cyclic straining. In contrast, the MHT material contains a bimodal $\gamma$ " distribution where large $\gamma$ " precipitates cannot be sheared easily and the loss of coherency is not as severe as for the fine $\gamma^{\prime \prime}$ precipitates. As a result, cyclic softening is not as noticeable in the MHT material as in the SHT material [3]. Cyclic softening of a material is considered delcterious because the load bearing capacity of the material is reduced with cyclic strain accumulation. 

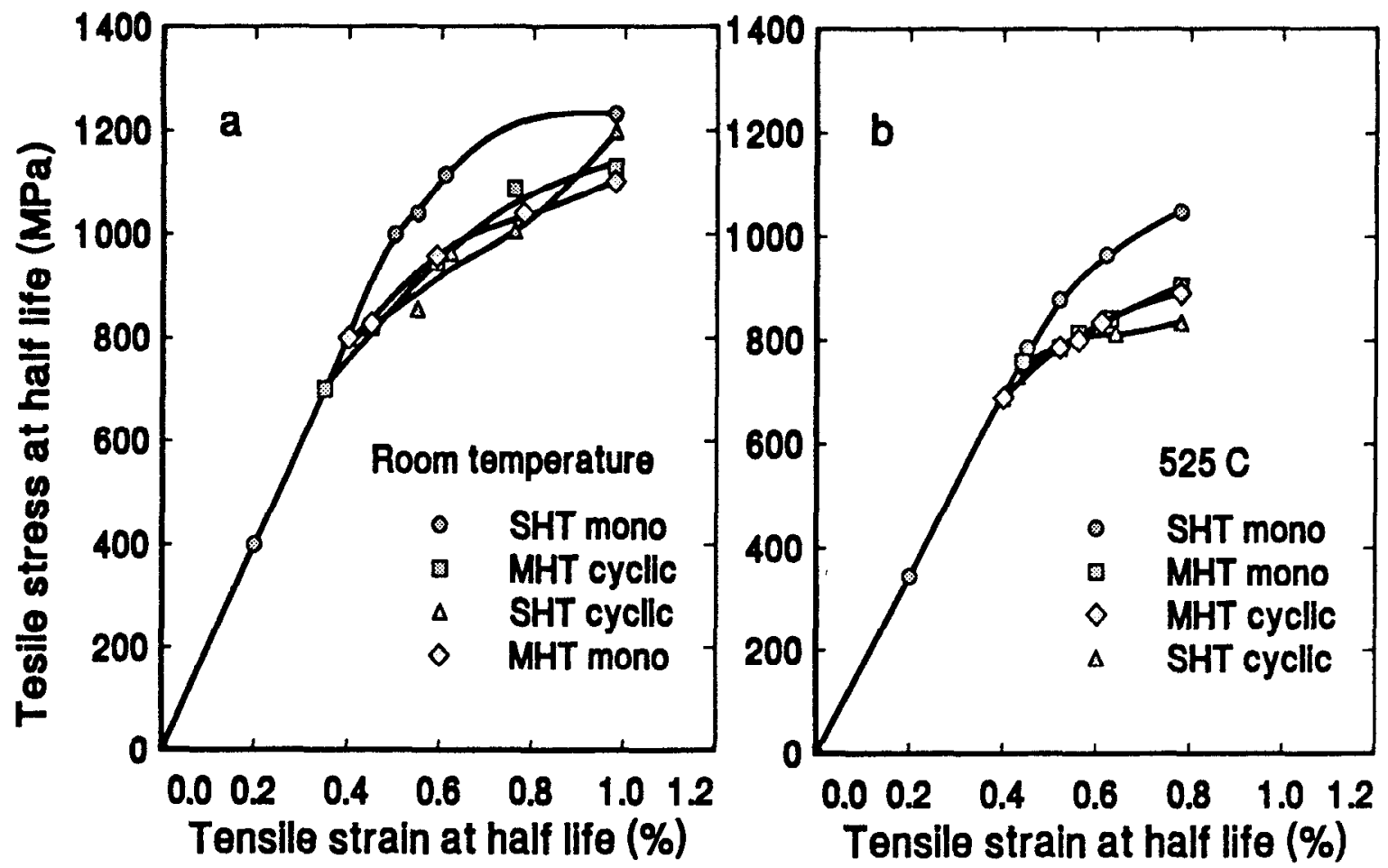

Fig. 6 Comparison of monotonic and cyclic stress-strain response of Alloy 718 materials at (a) RT and (b) $525^{\circ} \mathrm{C}$.

A major concern about the fatigue crack initiation behaviour of Alloy 718 turbine disc material, subjected to the MHT, relates to its notch sensitivity due to the presence of grain boundary $\delta$ phase. A comprehensive literature review on the notch sensitivity of Alloy 718 has been conducted by Sjoberg, Ingesten and Carlson [8]. They suggest that film-like $\delta$ morphology at the grain boundaries renders Alloy 718 notch sensitive whereas $\delta$ phase precipitates that protrude from the grain boundaries into the grain interiors, such as the one presented in the MHT material, can effectively act as grain boundary strengtheners. Preliminary results on the notch sensitivity of the MHT material, where double edge notch (DEN) specimens were used in load controlled fatigue tests, suggested that MHT renders Alloy 718 notch sensitive, particularly under high cycle fatigue loading conditions [9]. However, in that investigation, the notches in the DEN specimens were machined by wire electro-discharge machining (EDM) technique which leaves a thin cast layer on the notch surface. The nature of the cast layer is expected to be microstructure dependent particularly in the grain boundary regions. The results generated on DEN specimens for the SHT and MHT materials thus far are not conclusive and current work is underway to test DEN specimens machined using the same techniques as those used to machine the turbine disc bolt holes or rim slots such as reaming or broaching [9]. These DEN specimens will be tested in a shot peened condition using shot peening parameters similar to those used to process the turbine discs. It is hoped that relative to the SHT matcrial, shot pecning will introduce a larger residual compressive stress zone in the MHT material because of its lower yield strength and the fatigue strength of both materials, in the vicinity of the notches, will be comparable. This hypothesis is however purely conjectural at present and it needs experimental verification.

\section{Conclusions}

Relative to the standard heat treatment, the modified heat treatment changes different mechanical properties of Alloy 718 in the following manner.

1. It decreases the $0.2 \%$ offset yield strength of the material at room temperature, $525^{\circ} \mathrm{C}$ and $650^{\circ} \mathrm{C}$ with no change in the modulus of elasticity. 
2. It improves creep life by a factor of $\sim 1.5$ to 2 at $650^{\circ} \mathrm{C}$ by extending the tertiary creep life with no change in the minimum creep rate of the material.

3. It decreases the FCGR's by a factor of -2 at $525^{\circ} \mathrm{C}$ and $650^{\circ} \mathrm{C}$ over a wide range of $\Delta \mathrm{K}$ values with no loss in fatigue crack growth resistance at room temperature.

4. In strain controlled LCF tests, it decreases the LCF life by factors of 3,2 and 1.5 at $\mathrm{RT}, 525^{\circ} \mathrm{C}$ and $650^{\circ} \mathrm{C}$ respectively. However, cyclic stability of the material is improved at all test temperatures.

5. Further work is required to precisely quantify the notch sensitivity of the SHT and MHT Alloy 718 materials using specimens representative of a turbine disc bolt hole and rim slot surface conditions.

\section{Acknowledgement}

This work was conducted under IAR-NRC project JHM00 and the financial assistance for this project was provided by the chief of the Research and Development, Department of National Defence, Canada under financial arrangement 220787NRC06.

\section{References}

[1] A.K.Koul, P.Au, N.Bellinger, R.Thamburaj, W.Wallace, and J-P.Immarigeon, "Development of a Damage Tolerant Microstructure for Inconel 718 Turbine Disc Material", SUPERALLOYS 1988 Book, Ed. D.N.Duhl et al, TMS-AIME, 1988, pp.312.

[2] S.D.Antolovich, "The effect of Metallurgical Instabilities on the Behaviour of IN718", Superalloy 718 -- Metallurgy and Applications Book, Ed. E.A. Loria, TMS-AIME, 1989, pp.647-653.

[3] Hong Bande, Yi Xiao, P.Au, A.K.Koul, and W.Wallace, "Low Cycle Fatigue Fracture Behaviour of Conventional and Damage Tolerant Microstructures of Inconel 718 at $650^{\circ} \mathrm{C} "$, SURFACE ENGINEERING Book, Ed. S.A.Meguid, Elsevier Applied Science, 1990, pp.238-251.

[4] M.R.Pishva, N.C.Bellinger, T.Terada, and A.K.Koul, "DC-PD Technique for Crack Length Measurements at Elevated Temperatures", IAR-NRC Report, LTR-ST-1635, Oct.1987, Canada.

[5] J.M.Poole, K.R.Stultz, and J.M.Manning, "The Effect of Ingot Homogenization Practice on the Structure and Properties of Wrought Alloy 718", Superalloy 718 -Metallurgy and Applications Book, Ed. E.A. Loria, TMS-AIME, 1989, pp.219-228.

[6] J.C.Beddoes and W.Wallace,"Heat Treatment of Hot Isostatically Processed IN-738 Investment Castings", Metallography 13: 185-194 (1980).

[7] L.A.James and W.J.Mills, "Effect of Heat-Treatment and Heat-to-Heat Variations in the Fatigue-Crack Growth Response of Alloy 718", Engineering Fracture Mechanics, vol.22.No.5, 1985, pp.797-817.

[8] G.Sjoberg, N.-G.Ingesten, and R.G.Carlson, "Grain Boundary $\Delta$-phase Morphologies, Carbides and Notch Rupture Sensitivity of Cast Alloy 718", Superalloys 718, 625 and Various Derivatives Book, Edited by E.A. Loria, TMS-AIME, 1991, p.603-621.

[9] R.G.Andrews, A.K.Koul, and P.Au, "Fatigue Crack Initiation in Alloy 718 at $650^{\circ} \mathrm{C}$ ", Superalloys 718, 625 and Various Derivatives Book, Ed. E.A. Loria, TMS-AIME, 1991, pp.943-954. 